\title{
SUPEREXPLORAÇÃO DA FORÇA DE TRABALHO E AS CONDIÇÕES DE TRABALHO NA PANDEMIA: CONSERVADORISMO E A QUESTÃO ÉTNICO- RACIAL*
}

Ana Cristina Oliveira de Oliveira

Marcela Soares

\section{INTRODUÇÃO}

Nosso capítulo busca resgatar a apreensão da superexploração da força de trabalho sob a análise do capitalismo dependente como possibilidade de pensarmos tanto o aprofundamento da precarização das condições de trabalho, como o recrudescimento da feição fascistizante e violenta do Estado autocrático burguês brasileiro, reproduzido no histórico pensamento conservador, alavancados neste período da pandemia do novo coronavírus.

A contribuição do pensamento social brasileiro marxista auxilianos a uma crítica radical sobre a formação socioeconômica brasileira, que constituiu junto ao pensamento conservador, em sua modernização burguesa, um estado autocrático-burguês racista. Uma autocracia burguesa heteronômica e compósita expressa nos elementos da democracia restrita, do autoritarismo e do fascismo, que, portanto, garantem o apassivamento das classes trabalhadoras seja pela violência explícita ou pela cooptação para garantir a manutenção dos seus superprivilégios via superexploração da força de trabalho e espoliação.

Pensamos nessa linha argumentativa a questão étnico-racial enquanto uma mediação fundante nos dilemas da resolução da questão nacional e democrática para a conquista da emancipação humana.

*DOI - 10.29388/978-65-86678-37-6-0=f.105-130 


\section{SUPEREXPLORAÇÃO DA FORÇA DE TRABALHO E O TRA- BALHO NA PANDEMIA}

A apreensão sobre o capitalismo dependente dispõe de importantes contribuições do pensamento social brasileiro, como o pensamento florestaniano, as obras de Clóvis Moura e a Teoria Marxista da Dependência (TMD). Temos o propósito de resgatar os aportes do pensamento social brasileiro marxista para apontarmos elementos do processo de modernização burguesa. Assim como, ressaltar como se constitui a precariedade do trabalho através da mercantilização da força de trabalho e os elementos da precarização contemporânea das condições de trabalho. Com isto, evidenciamos a superexploração da força de trabalho como marca fundante do capitalismo dependente e o conservadorismo irracional nesta fase do capitalismo contemporâneo.

Florestan Fernandes ao longo de suas produções teóricas, a partir de meados dos anos 1960, garantiu inteligibilidade da formação das nossas classes sociais, do capitalismo dependente, do caráter autocrático do Estado brasileiro e, por sua vez, da democracia restrita, mediada pela dupla depleção permanente sobre a força de trabalho latino-americana, a sobreapropriação de excedente ou superexploração. Ruy Mauro Marini, na mesma época quando eclode o movimento contrarrevolucionário da burguesia latino-americana, apreende, fundamentalmente a partir da teoria do valor, elementos cruciais da forma particular como o capitalismo se constitui nas formações socioeconômicas latinoamericanas. Marini traz, portanto, a apreensão da superexploração da força de trabalho, do caráter de contrainsurgência do Estado burguês latinoamericano e das democracias "viáveis" ou "restringidas" que se constituíram (MARINI, 2018).

Ambos os autores, assim como Clóvis Moura, ainda que guardadas algumas diferenças dos aportes teórico-epistemológicos, oferecem elementos convergentes para apreendermos as modificações tensionadas pelo capitalismo contemporâneo sob a dependência. Nessa direção, os reivindicamos para a análise da nossa formação socioeconômica no contexto atual da pandemia do novo coronavírus que impõe o aprofunda- 
mento das contradições destrutivas do capitalismo em sua crise estrutural. $^{1}$

Como podemos constatar a exemplo do aumento do preço de alguns alimentos da cesta básica das classes trabalhadoras brasileiras, ${ }^{2}$ os laços da dependência têm sido agravados com o aprofundamento da cisão das necessidades das massas com a esfera produtiva. Essa é uma característica particular do ciclo do capital no capitalismo dependente que tanto a TMD como Florestan Fernandes trazem, a partir de diferenciadas análises, como intrínsecas à passagem da situação colonial para o capitalismo dependente com a não resolução da questão nacional, da questão democrática e da questão étnico-racial. ${ }^{3}$

"Sob a égide desse capitalismo dependente, a América Latina continuou a produzir excedente econômico para fora, diferenciando e revitalizando, através de sua peculiar 'revolução burguesa', os interesses internos que subordinam o seu desenvolvimento aos dinamismos das nações capitalistas avançadas" (FERNANDES, 2010, p. 162). Elementos estruturantes nos processos de modernização burguesa em nosso país que se explicitam neste período da contrarrevolução preventiva e prolongada. ${ }^{4}$

A morte de milhares de trabalhadoras e trabalhadores negras/os, das franjas mais depauperadas das classes trabalhadoras, nesta pandemia, como também o extermínio dos povos originários demonstra com toda força, neste momento de exacerbamento da crise do capital, o patriotis mo entreguista característico das nossas burguesias antinacionais, racistas e antissociais. ${ }^{5}$

Os dados revelam que com a pandemia e o isolamento social, os/as trabalhadores/as informais foram duramente impactados/as atin-

\footnotetext{
${ }^{1}$ Mészáros (2009).

2 Brasil de Fato. Boletim Ponto. "Se não tem arroz, que comam macarrão". Disponível em: < https://www.brasildefato.com.br/2020/09/11/se-nao-tem-arroz-que-comam-macarrao $>$.

Acesso em: 12 set. de 2020.

${ }^{3}$ Ver Fernandes (2010).

${ }^{4}$ Florestan Fernandes (2019).

${ }^{5}$ Florestan $(2009,2011)$ garante a apreensão de que temos uma burguesia que é "antissocial" no sentido da expropriação do trabalho, das exportações do excedente econômico, que geram o aumento das desigualdades econômicas e das tensões sociais. Estas são limitadas pelo caráter "antinacional" das burguesias locais ao promoverem a repressão ou cooptação dos movimentos sindicais e das vanguardas políticas das classes trabalhadoras.
} 
gindo mais da metade $(56 \%)$ da perda de rendimento em comparação aos formais, que apresentaram 26\% de redução da renda (IBGE, 2020). Nesse contexto, o auxílio emergencial tem sido essencial para cobrir boa parte da perda de rendimento, pois entre os/as trabalhadores/as que continuaram em atividade, mas que perderam renda, metade recebeu o auxílio emergencial. Para $76 \%$ dos/as ocupados/as cujos rendimentos foram reduzidos e que conseguiram acessar os $\mathrm{R} \$ 600$ de auxílio, o valor do benefício foi suficiente para cobrir as perdas. Entre os/as ocupados/ as que receberam $R \$ 1.200$ como auxílio, $92 \%$ tiveram as perdas cobertas (IBGE, 2020).

Aumentou abissalmente o desemprego no país, que hoje são de 12,8 milhões de desocupados, dados do segundo trimestre de 2020 do Instituto Brasileiro de Geografia e Estatística (IBGE, 2020), com uma taxa de desocupação de 11,8\%, 5,7 milhões e 29,1\% de taxa de subutilização. Segundo a análise do Ricardo Antunes, temos aí uma abundante massa de sobrantes de trabalhadores/as. Ao analisar o futuro do trabalho no Brasil e a nova massa superexplorada da era dos serviços digitais, Antunes (2019a, s/p) afirma que

O desemprego é o flagelo mais brutal. E cada vez mais esse bolsão de desempregados se confunde com o bolsão de subempregados, de informais intermitentes, porque todos esses vivenciam muitos horários de suas vidas em que deveriam trabalhar para sobreviver, na condição real de desemprego.

Não podemos ignorar que os/as trabalhadores/as destituído/as da proteção social pelos direitos sociais, trabalhistas e previdenciários realizam a produção e reprodução do capital em uma sociabilidade destrutiva que os/as leva ao sofrimento, adoecimento e morte. Como pôde ser visto na saída para o trabalho daqueles/as, que sem alternativas para a sobrevivência, foram impelidos/as para o rompimento com as medidas de isolamento social, sem prévia organização e proteção do Estado para o enfrentamento da pandemia.

Nessa direção, o capitalismo tem assumido contornos ainda mais trágicos e desumanos nos últimos anos, com a aprovação das contrarreformas trabalhista e previdenciária. O resultado da intensificação pro- 
gressiva da exploração da força de trabalho estruturada pela política macroeconômica neoliberal e pela reestruturação produtiva permanente, não poderia ser outro, senão os/as milhares de desempregados/as, desalentados/as com condições cada vez mais precarizadas, aumentando as fileiras da superpopulação relativa. Condição que contribui para o sobretrabalho da parte ocupada e o rebaixamento do valor da força de trabalho.

$\mathrm{Na}$ análise da teoria marxista da dependência apreende-se a superexploração da força de trabalho como a não correspondência da remuneração da força de trabalho com o seu valor e enquanto tendência particular da condição da dependência. Alicerçada pela cisão nas fases do ciclo do capital, ou seja, a cisão entre a esfera produtiva com as necessidades das massas e pela transferência de valores como intercâmbio desigual entre os países periféricos e as nações hegemônicas (AMARAL; CARCANHOLO, 2009; LUCE, 2018). A marca da superexploração da força de trabalho aponta para

[...] o fato de que são negadas ao trabalhador as condições necessárias para repor o desgaste de sua força de trabalho: nos dois primeiros casos, porque ele é obrigado a um dispêndio de força de trabalho superior ao que deveria proporcionar normalmente, provocando-se assim seu esgotamento prematuro; no último, porque se retira dele inclusive a possibilidade de consumir o estritamente indispensável para conservar sua força de trabalho em estado normal (MARINI, 2000, p. 126).

Em relação a esta configuração da superexploração da força de trabalho intensificada pela pandemia, antes, a contrarreforma trabalhista ao normatizar a terceirização (Lei 13.429/17) e o trabalho intermitente (Lei $13.467 / 7)^{6}$ reconfigurou a jornada de trabalho, que, legalmente, era

\footnotetext{
${ }^{6}$ Com a pandemia, o patronato intensifica os contratos intermitentes chegando a criar 20,5 mil vagas, empurrando a massa trabalhadora para jornadas intensas sem limites de horário subjugado ao pagamento abaixo dos níveis necessários para sobrevivência. A explosão do setor de serviços, nos últimos cinquenta anos, à guisa da privatização deste setor, embalado pela geração do lucro, tem sido explorado pelas grandes corporações capitalistas, marcando o mundo informacional digital. "O resultado é um novo proletariado de serviços da era digital" (ANTUNES, 2019a, s/p.) amparado pelo avanço destruidor do trabalho digital, on-line e intermitente nos últimos anos.
} 
de 8 horas/dia, com possibilidade de duas horas extras (HE) e duração de $44 \mathrm{~h} /$ semana. Com a contrarreforma foi alterada para 12 a 14h/dia, sem pagamento de $\mathrm{HE}$, totalizando $48 \mathrm{~h} /$ semana. Acrescenta-se a isto, uma maior rotatividade; a exigência de metas; o aumento de problemas de saúde mental e de assédio moral. Com tudo isso, não poderia ter um resultado diferente senão o aumento da carga de trabalho e o desgaste da saúde física e mental sugados pela produção e reprodução social do trabalho, a exemplo do trabalho da mulher grávida que era proibido em locais insalubres, mas agora é permitido mediante atestado médico que o autorize, com possíveis reflexos sobre a saúde do nascituro (LACAZ, 2019).

Nesse sentido, Marini (2000) ao compreender a estrutura da divisão internacional do trabalho e do seu desenvolvimento desigual, identifica três características que marcam o modo de produção fundamentado na superexploração do/a trabalhador/a. Estas características revelam o aspecto que representa relação direta ao baixo grau de desenvolvimento das forças produtivas na economia latino-americana e o que se reproduz nesta região. Quais sejam: o prolongamento da jornada de trabalho, a intensificação do trabalho e a expropriação de parte do trabalho necessário para restituir sua força de trabalho.

O cenário brasileiro atual, sob um governo negacionista, avança no estrangulamento do enfrentamento de uma doença altamente transmissível. Como podemos identificar no levantamento do Departamento Intersindical de Estatística e Estudos Socioeconômicos (DIEESE), que aponta os primeiros impactos da pandemia no mercado de trabalho até maio de 2020, revelando que 26,3 milhões de brasileiros/as declararam não ter trabalhado nem procurado trabalho, mas que gostariam de estar trabalhando. Entre eles/as, 18,5 milhões afirmaram estar nessa situação por causa da pandemia. Do total de ocupados/as, 19,0 milhões estavam afastados/as do trabalho e 30 milhões tiveram alguma redução no rendimento do trabalho comparado ao mesmo período do ano passado com a redução média do rendimento de 61\%. Desses, 15,7 milhões disseram que o motivo do afastamento era a pandemia e 9,7 milhões relataram ter deixado de receber remuneração. Cerca de 61\% dos/as ocupados/as 
afastados/as das atividades tiveram perda média de 49\% nos rendimentos (DIEESE, 2020).

Segundo os dados, as perdas de rendimento foram maiores entre os/as ocupados do setor de serviços, do comércio e da construção civil e entre os/as trabalhadores/as informais. Assim como, as perdas de rendimento entre os/as ocupados/as em serviços essenciais na pandemia, como os/as entregadores/as e os/as trabalhadores/as da saúde e da limpeza (parcela significativa de trabalhadores/as nos espaços populares).

Dá para dizer que ela (a contrarreforma trabalhista) escravizou. $\mathrm{Na}$ escravidão, o senhor de escravo comprava o escravo, na terceirização ele aluga. A contra Reforma Trabalhista do Temer [veio] para quebrar a espinha dorsal da CLT. A prevalência do negociado sobre o legislado. A ideia de flexibilidade da jornada e do salário. A piora das condições de salubridade. Até coisas perversas, como as trabalhadoras e os trabalhadores têm que comprar seus uniformes. O transporte antes era uma obrigação das empresas, não é mais (ANTUNES, 2019b, s/p).

Interessante destacar que o "negociado sobre o legislado" (SEVERO; MAIOR, 2017), implementado pela contrarreforma trabalhista, enfraquece a sustentação financeira dos sindicatos e dificulta a atuação para responder às demandas coletivas dos trabalhadores. Porque torna-se opcional a contribuição sindical, desobrigando o imposto sindical, instituído nos tempos de Getúlio Vargas.

Apesar de se apresentar enquanto uma modernização da CLT e como possibilidade de geração de empregos, as medidas da contrarreforma trabalhista trouxeram: o aumento do desemprego e do trabalho precário; o aumento dos acidentes de trabalho; maior desgaste físico-psíquico, com aumento das doenças mentais do trabalho; maior demanda para o SUS pela precariedade das condições e ambientes de trabalho.

Esses dados nos indicam que não se justifica, portanto, a argumentação sobre a criação de novos empregos com o trabalho intermitente e que o trabalho vem pautando o contorno da curva pandêmica no cenário de superexploração da força de trabalho, pois “[...] a automação é 
para aumentar a produtividade do capital [e] para reduzir a força de trabalho, que é tratada como custo" (ANTUNES, 2019a, s/p).

Percebe-se, claramente, o aumento exponencial da superpopulação relativa e a elevação dos índices de desigualdade econômica, social e étnico-racial, que assola de sobremaneira os/as trabalhadores/as. Portanto, a precarização das relações de trabalho com a redução de salários e a perda de rendimentos sem garantias de direitos trabalhistas expressa a condição da dependência na dinâmica da divisão internacional do trabalho.

Portanto, a partir de Florestan Fernandes (2019, p. 88) ressaltamos que "tudo isso desenha o quadro do capitalismo selvagem da periferia”, sob o capitalismo monopolista, quando a reação burguesa constituiu, sob a face do autoritarismo, o Estado autocrático burguês

Nascido do contexto de uma contrarrevolução política, para garantir a "modernização", a incorporação e a industrialização maciça, pelo menos em um certo período de tempo deve funcionar como o instrumento político de uma ditadura de classe aberta. Sob outros aspectos, esse Estado também se adapta às suas funções contrarrevolucionárias e repressivas através de várias inovações. Ele não se transforma para pôr em prática um "bonapartismo", mas para servir a interesses contraditórios das classes burguesas (FERNANDES, 2019, p. 86).

É nesse sentido, que a conformação do Estado neoliberal ${ }^{7}$ nas economias latino-americanas vislumbra reduzir ainda mais a face restrita das democracias. Porque "[...] em sua fase de declínio, o capitalismo intensifica o número de suas contradições intrínsecas” (FERNANDES, 2019, p. 94). Com isso, na versão latino-americana a política macroeconômica neoliberal garantiu o compromisso violento entre as burguesias nativas e as burguesias externas, com um movimento apassivador de

\footnotetext{
${ }^{7}$ Conforme a análise de Harvey (2008, p. 6) o Estado neoliberal tem sua fundamentação numa estrutura institucional caracterizada por sólidos direitos a propriedade privada, livres mercados e livre comércio. Nestes termos, "o papel do Estado é criar e preservar uma estrutura institucional apropriada a essas práticas; o Estado tem de garantir, por exemplo, a qualidade e a integridade do dinheiro. Deve também estabelecer as estruturas e funções militares, de defesa, da polícia e legais requeridas para garantir direitos de propriedade individuais e para assegurar, se necessário pela força, o funcionamento apropriado dos mercados.
} 
uma democracia de cooptação presente, principalmente, nos governos do Partido dos Trabalhadores (PT).

Desde os governos do PSDB, as contrarreformas consolidam o fundo público ${ }^{8}$ como uma das principais formas de proteger o capital diante da sua crise estrutural e reafirmam a nossa condição dependente. "Neste percurso de nítida contrarrevolução para implementar as contrarreformas, o capitalismo brasileiro em crise demonstra que a sua burguesia antinacional e antissocial encaminha de forma brutal todos os encargos para a classe trabalhadora" (OLIVEIRA; SOUZA; SOARES, 2019, p. 20).

Portanto, hoje as classes dominantes na defesa de uma agenda ultraneoliberal disputam econômica, social e politicamente, com entusiasmo religioso neopentecostal, o horizonte de liquidar qualquer resquício de Estado democrático. Sendo assim, "o elemento conservador é quando pretende-se manter uma ordem social que não [tem] disposições suficientes para compor a autonomia necessária para o desenvolvimento de uma Nação" (FERNANDES, 2009, p. 32-33). É neste bojo da reação burguesa e da heteronomia que se desdobram as ideologias conservadoras no Brasil.

\section{CONSERVADORISMO E ESTADO AUTOCRÁTICO-BUR- GUÊS RACISTA}

No âmago da atual tragédia sanitária sob uma democracia restrita e um governo negacionista, este enorme contingente de trabalhadores/ as, sob a superexploração da sua força de trabalho são penalizados/as pelas consequências de uma maior precarização ocasionadas pelas contrarreformas, enquanto expropriações de direitos, assim como pelas medidas político-econômicas neste período da pandemia do novo coronavírus.

É fundamental destacar que a democracia restrita é uma das faces do nosso Estado autocrático, “[...] (o qual não é apenas uma imagem in-

\footnotetext{
8“Reduzindo sua ação como salário indireto e ampliando seu papel de financiador e subsidiário do seu processo de acumulação e valorização, em especial enquanto alimentador do capital porta dor de juros" (OLIVEIRA; SOUZA; SOARES, 2019, p. 19-20).
} 
vertida do Estado democrático-burguês, porém a forma que ele deve assumir como instrumento de dominação externa e de um despotismo burguês reacionário)" (FERNANDES, 2019, p. 82). Este Estado autocrático-burguês, desse modo, é produto de como se transformaram as classes dominantes, no processo de modernização burguesa, ressignificando o padrão de privilégio de poder e de prestígio de uma sociedade de castas e estamentos em suas relações sociais cotidianas, explícita também na degradação da exploração da força de trabalho.

Nesse sentido, o capitalismo dependente brasileiro completou a sua revolução burguesa, mas historicamente expressa formas aparentemente "incompletas" e/ou "deformadas" do processo da sua "modernização do arcaico" e "arcaização do moderno". Uma revolução burguesa que não resolveu a questão nacional, a questão democrática e a questão étnico-racial para não acordar "o homem nativo" para as possibilidades de uma participação ampliada e não ferir os superprivilégios das classes dominantes. Florestan (2015) aponta, portanto, para a compreensão dos enfrentamentos na atualidade, sobre os mecanismos de apropriação das classes dominantes (burguesia) para a manutenção do poder, ainda que na presença marcante das lutas dos de "baixo". Em seus escritos, revela que o desenvolvimento do capitalismo na América Latina mantém e reproduz aspectos da política colonial e se enraíza nos laços de dependência e submissão aos interesses do imperialismo.

Florestan (2015) nos leva a apreender as fragilidades estruturais da formação das classes trabalhadoras que favorecem para uma construção de uma posição menos "ofensiva" e, por outro lado, avança na compreensão do desenvolvimento capitalista estruturado na forma "autocrática” de organização e de exercício do poder, configurada pela forma particular de como o capitalismo se institucionalizou e difundiu-se na América Latina. E enriquece nas análises das classes na América Latina, quando observa que as classes não são diferentes aqui, mas a diferença se configura no modo pelo qual o capitalismo se objetiva e se irradia historicamente como força social (FERNANDES, 2009). 
O conservadorismo9 ${ }^{9}$, como fundamento teórico-ideológico das classes dominantes na história do nosso país, exibe características mais ofensivas do seu "mandonismo oligárquico" em determinados períodos históricos. Reconhecemos que toda classe dominante apresentará o conservadorismo como forma político-ideológica de manutenção do seu poder. No entanto, no caso brasileiro, as oligarquias agrárias se aburguesaram e mesmo aquelas burguesias urbanas trouxeram os laços provincianos, além da subordinação econômica, dos setores agrários. Portanto, o sujeito da revolução burguesa no Brasil era, majoritariamente, um segmento da oligarquia cafeeira, escravocrata, que não se separa dele. Ao contrário, depende de recursos dele, ou seja, da própria estrutura agrária. Portanto, historicamente consolida alianças pelo alto com os oligarcas excluindo a maioria do povo. Dessa forma, será uma classe dominante que pode apresentar um discurso democratizante, mas nunca fora a "paladina da civilização". Isso porque a relação de heteronomia com as nações hegemônicas, que assume na passagem da condição colonial ao capitalismo dependente, exige frequentes pactos conciliatórios pelo alto, impedindo avanços democratizantes.

É sob este ângulo, quando abordamos o conservadorismo, exigese o reconhecimento da consolidação do papel do Estado autocráticoburguês e do fortalecimento da Igreja Católica - engendrado pelo colonialismo e pelo escravismo, como eixos principais, e estabelecido na difusão da suposta democracia racial ${ }^{10}$ configurada na desigualdade de condições de vida e trabalho que o/a negro/a foram condicionado/a no PósAbolição.

A transição do trabalho escravo para o assalariado que marca a formação das classes trabalhadoras brasileiras eleva a constituição da superpopulação relativa protagonizada eminentemente pela massa de trabalhadores/as negros/as. Os homens negros foram reconhecidos como

\footnotetext{
${ }^{9}$ A expressão conservadorismo é utilizada aqui para nos referirmos a uma articulação das classes dominantes que tem como perspectiva o retrocesso na história dos direitos da classe trabalhadora. Vale ressaltar que a matriz ideológica do conservadorismo é, sem dúvida, o pensamento de Edmund Burke. Para maiores informações ver (ESCORSIM NETTO, 2011).

${ }^{10}$ Ver Moura (1983) e Fernandes (2010).
} 
Indolentes, cachaceiros, não-persistentes para o trabalho e, em contrapartida, por extensão, apresenta-se o trabalhador branco como o modelo perseverante, honesto, de hábitos morigerados e tendências a poupança e à estabilidade no emprego. Elege-se o modelo branco como sendo o do trabalhador ideal (MOURA, 1988, p. 69).

A este conjunto de características ofensivas um elemento é crucial: a inserção do/a negro/a foi absorvida, a partir do racismo científico, como um elemento negativo da formação da sociedade brasileira. Com isso, a “[...] nossa trajetória histórica é marcada por esses dois modelos sucessivos, primeiramente o escravista comandado pelo sistema colonialista e logo após o capitalismo dependente dominado pelo sistema imperialista" (MOURA, 1983, p. 134). As determinações do poder das elites brasileiras, marcadas pela aliança do latifúndio com o imperialismo, fundamentam os elementos ideológicos racistas contribuindo para ratificar o imperativo do/a negro/a à imposição na condição de exército industrial de reserva.

A formação das classes trabalhadoras, permeada pelo racismo estrutural, ${ }^{11}$ conforma a intensificação da superexploração da força de trabalho sobre o proletariado negro. Esta conformação na dinâmica do capitalismo dependente brasileiro, intrínseca à constituição da divisão internacional do trabalho, em outros termos, no sistema capitalista internacional, edifica na força de trabalho da população negra o lugar "desqualificado" na absorção desta massa de trabalhadores na produção. Assim, Florestan revela cuidadosamente a situação da população negra imediatamente no Pós-Abolição e na formação recente de uma sociedade capitalista.

Onde a produção se encontrava em níveis baixos, os quadros da ordem tradicionalista se mantinham intocáveis: como os antigos libertos, os ex-escravos tinham de optar, na quase totalidade, entre a reabsorção no sistema de produção, em condições substancialmente análogas às anteriores, e a degradação de sua situação econômica, incorporando-se à massa de desocupados e de semi-ocupados da economia de subsistência do lugar ou outra região. Onde

\footnotetext{
${ }^{11}$ Sugerimos ver a grandiosa contribuição sobre o racismo estrutural do Silvio Almeida (2019).
} 
a produção atingia níveis altos, refletindo-se no padrão de crescimento econômico e de organização do trabalho, existiam reais possibilidade de criar um autêntico mercado de trabalho: aí, os exescravos tinham de concorrer com os chamados 'trabalhadores nacionais' (FLORESTAN, 2008, p. 31-32).

A estrutura racista da sociedade brasileira conta com o movimento conservador eugenista e desenvolve cientificamente teorias racistas no Brasil edificadas num acervo intelectual de concepções sobre a diferença entre raças quanto à sua constituição mental. Estes intelectuais aprimoram as concepções de que a população negra, incluindo os/as indígenas e "mestiços" são inferiores biologicamente na relação com o branco para o trabalho e para o desenvolvimento do país. Dentre os diversos pensadores conservadores brasileiros ${ }^{12}$ que embalam nesta produção, destacamos o médico psiquiatra eugenista Raimundo Nina Rodrigues (18621906) pela expressão e adesão de suas ideias sobre a superioridade branca ao argumentar que a "[...] constituição orgânica do negro, modelado pelo habitat físico e moral em que se desenvolveu, não comporta uma adaptação à civilização das raças superiores" (RODRIGUES, 2010, p. 289).

Para o Nina Rodrigues os/as negros/as africanos/as são o que são: nem melhores nem piores que os/as brancos/as. Simplesmente pertencem a uma outra fase do desenvolvimento intelectual e moral. Em sua argumentação, objetiva qualificar a população negra e indígena, e aí inclui a "mestiça" como sujeitos inferiores biologicamente e incapazes de realizar determinadas funções ocupacionais no mercado de trabalho, sendo relegados à sua inferiorização. Nina Rodrigues reforma o argumento dizendo que os selvagens - negros e índios - teriam uma espécie de código de conduta próprio, determinado nos seus locais de origem e que apresentam enormes diferenças dos códigos de conduta dos povos ditos civilizados.

\footnotetext{
${ }^{12}$ Dentre os diversos pensadores do movimento eugenista como expressão do conservadorismo na importação das teorias europeias racialistas, destacamos o Renato Khel (1889-1974) Oliveira Viana (1883-1951), Silvio Romero (1851-1914), Manuel Bonfim (1868-1951); Gilberto Amado (1887-1969); Euclides da Cunha (1866-1909); Batista Lacerda (1846-1915); Belisário Penna (18681939); Monteiro Lobato (1882-1942) Edgard Roquette-Pinto (1884-1954), dentre outros. Em relação aos intelectuais do pensamento conservador brasileiro ver Skidmore (1976), e Schwarcz (2007), acrescido da eugenia no pensamento conservador desenvolvido por Góes (2018).
} 
Ora, desde que a consciência do direito e do dever, correlativos de cada civilização, não é o fruto do esforço individual e independente de cada representante seu; desde que eles [índios, negros e mestiços] não são livres de tê-la ou não tê-la assim, pois que essa consciência é, de fato, o produto de uma organização psíquica que se formou lentamente sob a influência dos esforços acumulados e da cultura de muitas gerações; tão absurdo e iníquo, do ponto de vista da vontade livre, é tornar os bárbaros e selvagens responsáveis por não possuir ainda essa consciência, como seria iníquo e pueril punir os menores antes da maturidade mental por já não serem adultos, ou os loucos por não serem sãos de espírito (RODRIGUES, 1957, p. 79).

A condição do/a negros/a no interior do conjunto dessa massa de trabalhadores/as excedentes configura uma série de especificidades, destituídos dos bens materiais, permanece no lastro histórico com as mesmas condições. Nesta direção, o capitalismo dependente brasileiro concerne à ideologia da população negra e indígena à inferiorização de sua forma humana e com esta conformação exponencial da superexploração do/a trabalhador/a brasileiro/a, agravado pelas condições étnicoraciais, corporifica a categoria da superexploração no interior das análises da questão racial (FAGUNDES, 2020).

E por isso, podemos identificar as marcas da questão étnico-racial ao analisarmos os dados do IBGE $^{13}$ (2020) sobre as cores da desigualdade. As estatísticas apontam que o Brasil ainda se encontra distante de uma democracia racial. " $\mathrm{Na}$ verdade, nos acostumamos à situação existente no Brasil e confundimos tolerância racial com democracia racial" (FERNANDES et al., 2006, p. 172).

O campo do ideário conservador no horizonte da modernização no país, enquanto exigência do capitalismo internacional, estabeleceu a constituição de um projeto integrador, o reformista-conservador. (MATTOS, 2015). A reação burguesa à crise estrutural desde 1970, como uma reação conservadora contrarrevolucionária opera na sociedade brasileira como reação marcada pela intensificação da exploração do trabalho.

\footnotetext{
${ }^{13}$ Para maiores informações ver: $<$ https://agenciadenoticias.ibge.gov.br/agencia-noticias/2012agencia-de-noticias/noticias/21206-ibge-mostra-as-cores-da-desigualdade >. Acesso em: 28 ago. 2020.
} 
Avança nos fenômenos de "extrema-direita" aproximando as tendências irracionais ou de convergência decadente da "miséria da razão"14 (COUTINHO, 2010).

Para Marini, neste período da contrarrevolução burguesa, a integração imperialista desencadeia o aumento da superexploração da força de trabalho, o "aprofundamento da centralização do capital e da proletarização da pequena burguesia.” Promovendo

[...] a ruptura ou o abandono do que havia sido, até então, a norma na América Latina - o Estado populista, isto é, o "Estado de toda a burguesia" -, que favorecia a acumulação de todas as suas frações (embora estas usufruíssem desigualmente dos lucros disponíveis ao seu alcance). Em seu lugar, criou-se um novo Estado, que se preocupa fundamentalmente dos interesses das frações monopolistas, nacionais e estrangeiras, e estabelece, pois, mecanismos seletivos para favorecer a sua acumulação; as demais frações burguesas devem subordinar-se à burguesia monopolista, estando seu desenvolvimento em rigorosa dependência do dinamismo que alcance o capital monopolista, enquanto a pequena burguesia, embora sem deixar de ser privilegiada na aliança de classes na qual repousa o novo poder burguês, é forçada a aceitar uma redefinição de sua posição, perde importância política e fica ela também totalmente subordinada, com suas condições de vida vinculadas às iniciativas e ao dinamismo da burguesia monopolista (MARINI, 2018, p. 4-5).

A reação burguesa, frente aos novos rearranjos locais, e à crise estrutural do capital, apresentam-se com o irracionalismo como respostas reacionárias aos problemas, ocasionados pelas lutas de classes, consolidando um processo de decadência na filosofia burguesa com uma precariedade dos fundamentos e das argumentações sofísticas cada vez mais agudos, engendrando diferenciadas etapas do irracionalismo (LUKÁCS, 1976).

\footnotetext{
${ }^{14}$ Coutinho (2010) em "Estruturalismo e a miséria da razão" aprimora e atualiza a crítica da cultura burguesa do irracionalismo. No texto, analisa o empobrecimento da razão, recuperando o pensamento luckasiano, que integra, complementa e reforça os mitos irracionalistas. Em especial recupera os que transformam as regras formais intelectivas em realidade objetiva existente acima do ser social.
} 
Portanto, na realidade deste período de crise sanitária as forças burguesas recrudesceram consideravelmente o conservadorismo contemporâneo vinculado ao positivismo ${ }^{15}$ e ao irracionalismo, evidenciados com: o ultraneoliberalismo, o revisionismo e o negacionismo. Avançam, nesse caminho com as formas atuais de comunicabilidade e informação pelas redes sociais com fake news para garantir o trabalho vivo nas ruas com a flexibilização da quarentena para os "de baixo".

As contínuas expropriações ${ }^{16}$ configuradas também por meio das contrarreformas expressam a reação das classes dominantes ao conjunto de direitos conquistados ao longo das últimas décadas, e não de sua conservação. O conservadorismo aqui entendido como uma expressão, portanto, do movimento das classes dominantes em se opor, e em última instância, recuar ${ }^{17}$ o conjunto dos direitos conquistados das classes trabalhadoras. Atuam em defesa da preservação das relações sociais capitalistas, organizando movimentos, grupos e indivíduos. Como ideologia que emerge na crise, o conservadorismo junto ao irracionalismo chama para si a função de centro irradiador da defesa da sociedade burguesa.

Como apresentado acima, a burguesia brasileira nunca foi a paladina da civilização, ao contrário, com sua característica antinacional, racista e antissocial sempre se apresentou amparada a uma brutal violência no seu padrão de dominação e a sua hegemonia é garantida pelo autoritarismo e por seus traços fascistizantes.

No entanto, esta é uma agenda que precisamos avançar para a apreensão da radicalização da extrema-direita no Brasil, que se consolida e legitima o conservadorismo articulado ao cenário internacional ${ }^{18}$ de recomposição das forças e interesses das classes dominantes. As estratégias produzidas pela extrema-direita têm sido exaustivas. Podemos contar

\footnotetext{
${ }^{15}$ Abordar o conservadorismo contemporâneo no Brasil implica referir ao projeto reformistaconservador alinhado ao processo de consolidação do capitalismo no Brasil. Löwy (1987) ao dis cutir o conservadorismo aponta elementos que indicam o pensamento positivista de Comte e Durkheim como referências teóricas e ideológicas do pensamento conservador presente na legitimação da sociabilidade burguesa na construção do modo de produção capitalista.

${ }^{16}$ Sobre o debate atual das expropriações sugerimos ver Boschetti (2020) e Fontes (2020).

${ }^{17}$ Nestes termos, o conservadorismo seja clássico ou contemporâneo assume o protagonismo de uma reação burguesa anti-democrática como uma expressão do antagonismo dos distintos interesses na luta de classes que constituem da sociabilidade burguesa orientada na amenização da luta de classes com um conjunto de reformas. (IASI, 2007).

${ }^{18}$ Sugerimos ver Poggi (2016) e Demier e Hoeveler (2016).
} 
uma infinidade delas, mas destacamos o estreito alinhamento internacio$\mathrm{nal}^{19}$ e a atuação intensiva nas redes sociais e novas tecnologias. Assim como a sofisticação do léxico conservador; embasamento teórico, com vias à formação de quadros na juventude; a inserção nos espaços universitários; as disputas de eleições locais e parlamentares; a articulação com setores empresariais-evangélicos ${ }^{20}$ e do agronegócio e, em destaque a inserção nas comunidades dos espaços populares (favelas e periferias) (SOUZA; SITCOVSKY, 2020).

Trata-se, sobretudo, de aliar esforços no campo político, ideológico e teórico de enfrentamento aos quadros militantes de agora e nos próximos anos, por ser um projeto de curto, médio e longo prazo por parte das classes dominantes. Ou seja, conforma uma racionalidade e uma capacidade organizativa de se arraigar na sociedade brasileira, hoje mais afetada pelas condições de trabalho precarizado e intermitente, na era digital, que as classes trabalhadoras vêm enfrentando. Uma tragédia que vem permitindo um adensamento da extrema-direita no Brasil, com a possibilidade de um horizonte de ruptura com a política de conciliação de classes tal como conformada no período dos governos do PT.

Concordando com Ricardo Antunes, na sua obra recente "Coronavírus: o trabalho sob fogo cruzado" (ANTUNES, 2020, p. 14) sobre o que se espera das classes trabalhadoras analisa:

Pode-se imaginar, então, o tamanho da tragédia na periferia, nos tristes trópicos...como é o caso do Brasil. Desde logo, teremos uma massa de trabalhadores e trabalhadoras sem condições mínimas de sobrevivência, tangenciando ou vivendo uma fome profunda e sendo enterrada, aos milhares, nos cemitérios.

E acrescenta:

A esta simultaneidade e imbricação trágica entre sistema de metabolismo antissocial do capital, crise estrutural e explosão do coronavírus pode-

\footnotetext{
${ }^{19}$ Destacamos Steve Bannon com um dos principais articuladores e estrategistas da extrema direita em âmbito mundial, que foi preso recentemente. Sugerimos a reportagem "A viagem de Bolsonaro aos EUA e o projeto da extrema-direita mundial", disponível em: < https://esquerdaonline.com.br/2019/03/20/a-viagem-de-bolsonaro-aos-eua-e-o-projeto-da-extrema-direita-mundial/>.Acesso em: 28 mar. 2019.

${ }^{20}$ Ver Marcelo Badaró Mattos (2017).
} 
mos denominar, se quisermos usar uma síntese forte, capital pandêmico. Ele tem claro caráter discriminatório em relação às classes sociais, pois sua dinâmica é muito mais brutal e intensa para a humanidade que depende do próprio trabalho para sobreviver. A classe burguesa, incluindo seus séquitos de altos gestores, tem seus fortes instrumentos de defesa (recursos hospitalares privilegiados, condições de habitação que lhes permite escolher as melhores condições de realizar suas quarentenas, etc.), enquanto na classeque-vive-do-trabalho a luta é para ver quem consegue sobreviver.

Urge ressaltarmos a assimetria que vivemos no país e de como a pandemia escancara as desigualdades sociais e a questão étnico-racial. Materializa, de forma mais evidente, a desigualdade social e racial em um ambiente ameaçador de intensa expropriação de direitos e de vidas. No momento em que finalizamos este texto são mais de 145 mil mortes ocasionadas pelo novo coronavírus, a maioria é negra, ${ }^{21}$ e desde o início da pandemia no Brasil, o presidente Jair Bolsonaro expressou-se com indiferença com termos pejorativos e negacionistas que vão de: "É só uma gripezinha", "Não sou coveiro", "E daí?!" até o "Vamos tocar a vida".

Estamos falando de um governo negacionista, que exacerba a histórica política genocida da população negra e dos povos indígenas, com o objetivo de extinguir direitos e acabar com qualquer tipo de proteção daqueles/as que vendem sua força de trabalho. Além disso, um comando que exponencia a violência de todas as formas, como a racista e a patriarcal, seja pela expropriação dos povos originários pela via do desmatamento e das queimadas como possibilidade de aumento da fronteira agrícola. Ou no aumento exponencial da violência contra a mulher e o feminicídio, dentre outras violações de direitos do conjunto das classes trabalhadoras que vivem em precárias condições de moradia e urbanização nas cidades, prejudicadas pela periferização e interiorização da pandemia.

Não se pode ignorar que a democracia se encontra em um campo de batalha, marcada por perspectivas ideo-políticas distintas. "Até a metade do século XX, o pensamento de direita reagia criticamente ao fenô-

\footnotetext{
${ }^{21}$ Ver reportagem "Morrem $40 \%$ mais negros que brancos por coronavírus no Brasil", disponível em: <https://www.cnnbrasil.com.br/saude/2020/06/05/negros-morrem-40-mais-que-brancospor-coronavirus-no-brasil >. Acesso em: 20 jun. 2020.
} 
meno da democracia" (TEIXEIRA, 2010, p. 134). Portanto é vital reconhecermos, recuperando Wood (2003), que democratizar determina desmercantilizar, qual seja, um horizonte de incompatibilidade com o capitalismo.

Nestes termos, a perda do sentido democrático, consolidada na democracia restrita, vem tomando vulto, nos últimos tempos, de forma avassaladora sob a reação burguesa com a ressignificação das bandeiras de luta das classes trabalhadoras.

O reacionarismo conservador da burguesia antinacional, antissocial e racista, cada vez mais, com a ascensão de ideologias conservadoras e autoritárias, aponta para uma agenda de mais contrarreformas direcionada para o congelamento dos gastos públicos, como vista na Emenda Constitucional 95/2016, na terceirização ilimitada, no trabalho precarizado, intermitente, remoto e escravizado, representando mudanças nefastas no padrão de reprodução da força de trabalho, a partir do desmantelamento da legislação trabalhista e previdenciária, com o sufocamento e o esmaecimento das lutas e resistências populares.

Nosso texto buscou contribuir para o debate sobre o conservadorismo, as condições de trabalho e a questão étnico-racial no país, por meio do diálogo com o pensamento social brasileiro marxista, fundamental na análise do capitalismo sui generis ou selvagem na periferia do mundo, mas também buscamos evidenciar a perda progressiva dos parâmetros civilizatórios do capitalismo em âmbito global.

\section{REFERÊNCIAS}

ALMEIDA, S. Racismo Estrutural. São Paulo: Sueli Carneiro/ Pólen, $1^{\mathrm{a}}$ reimpressão. 2019.

AMARAL, M. S.; CARCANHOLO, M. D. A superexploração do trabalho em economias periféricas dependentes. Rev. Katál, Florianópolis, v. 12, n. 2, p. 216-225, jul./dez. 2009.

ANTUNES, R. Trabalho precário, intermitente, é a antessala do desemprego. Sociólogo analisa o futuro do trabalho no Brasil e a nova massa superexplorada da era dos serviços digitais. Brasil de Fato, São Paulo, 
29 abr. 2019a. Disponível em: <https://www.brasildefato.com.br/ 2019/04/29/trabalho-precario-intermitente-e-a-antessala-do-desemprego-diz-ricardo-antunes $>$. Acesso em: 02 set. 2020.

Coronavírus. O trabalho sob fogo cruzado. São Paulo: Boitempo, 2020.

Entrevista com Ricardo Antunes no Fórum do Acidente do Trabalho. Proletário digital (Ricardo Antunes) e Futuro do trabalho diante do desmonte do Estado. 26/09/2019b. Fórum Acidentes do Trabalho, s/d. Disponível em:_<https://www.forumat.net.br/at/?q=node/ 2425>. Acesso em: 28 ago. 2020.

BRASIL DE FATO. Boletim Ponto. "Se não tem arroz, que comam macarrão". Disponível em: <https://www.brasildefato.com.br/ 2020/09/11/se-nao-tem-arroz-que-comam-macarrao >. Acesso em: 12 set. 2020 .

BOSCHETTI, I. Limitações do Estado Social Capitalista Contemporâneo: expropriações, acumulação, exploração e violência. JMPHC Journal of Management \& Primary Health Care, v. 12, p. 1-13, abr. 2020. São Paulo. Disponível em: <https://www.jmphc.com.br/ jmphc/article/view/980>. Acesso em: 20 mai. 2020.

COUTINHO, C. N. O estruturalismo e a miséria da razão. 2. ed. São Paulo: Expressão Popular, 2010.

DIÁRIO OFICIAL DA UNIÃO. Edição extra. Lei 13.429/17 de 31.3.2017. Disponível em: <http://www.planalto.gov.br/ccivil_03/ _ato2015-2018/2017/lei/113429.htm>. Acesso em: 20 maio 2020.

Lei $\mathrm{n}^{\mathbf{0}}$ 13.467, de 13 de julho de 2017. Disponível em: <https://legis.senado.leg.br/norma/17728053/publicacao/17728664>. Acesso em: 20 maio 2020. 
Seção 1 Emenda Constitucional No 95, - 16/12/2016, Página

2 . Disponível em: <http://www.planalto.gov.br/ccivil_03/constituicao/emendas/emc/emc95.htm>. Acesso em: 20 maio 2020.

DEMIER, F.; HOEVELER, R. (orgs.). A onda conservadora: ensaios sobre os atuais tempos sombrios no Brasil. Rio de Janeiro: Mauad X, 2016.

DIEESE. Boletim emprego em pauta DIEESE (Departamento Intersindical de Estatística e Estudos Socioeconômicos. n. 15, jul. 2020. Disponível em: < https://www.dieese.org.br/boletimempregoempauta/ 2020/boletimEmpregoEmPauta15.html>. Acesso em: 15 set. 2020.

IBGE. IBGE mostra as cores da desigualdade. 11/05/2018. Disponível em: <https://agenciadenoticias.ibge.gov.br/agencia-noticias/2012-agencia-de-noticias/noticias/21206-ibge-mostra-as-cores-da-desigualdade $>$. Acesso em: 28 ago. 2020.

ESCORSIM NETTTO, L. O conservadorismo clássico: elementos de caracterização e crítica. São Paulo: Cortez, 2011.

FAGUNDES, G. G. O racismo no caso brasileiro e as raízes da superexploração do proletariado negro. Em Pauta, Rio de Janeiro, v. 18, n. 45, p. $55-68,1^{\circ}$ semestre de 2020 .

FERNANDES, F. Integração do negro na sociedade de classes. v. I. São Paulo: Editora Globo, 2008.

- Capitalismo dependente e classes sociais na América Latina. São Paulo: Editorial Global, 2009.

Circuito fechado: quatro ensaios sobre o "poder institucional". São Paulo: Globo, 2010. 
. Brasil em Compasso de Espera. Rio de Janeiro: UFRJ editora, 2011.

Poder e contrapoder na América Latina. 2. ed. São Paulo: Expressão Popular, 2015.

Apontamentos sobre a "Teoria do Autoritarismo". São Paulo: Expressão Popular, 2019.

FERNANDES, F.; PEREIRA, J. B. B.; NOGUEIRA, O. A questão racial vista por três professores. REVISTA USP, São Paulo, n. 68, p. 168179, fev. 2006. Disponível em: <http://www.revistas.usp.br/revusp/article/view/13491>. Acesso em: 10 set. 2020.

FONTES, V. Capitalismo filantrópico? Múltiplos papéis dos aparelhos privados de hegemonia empresariais. Revista Marx e o Marxismo, Niterói, v. 8, n. 14, p. 15-35, jan./jun. 2020.

GÓES, W. L. Racismo e Eugenia no pensamento conservador brasileiro. A proposta do povo em Renato Kehl. São Paulo: Liber Ars, 2018.

HARVEY, D. O Neoliberalismo: história e implicações. São Paulo: Ed. Loyola, 2008.

IASI, M. Processo de Formação da Consciência. São Paulo: Editora CPV, 2007.

IBGE. Desemprego. IBGE 2020. Disponível em: < https://www.ibge.gov.br/explica/desemprego.php>. Acesso em: 12 set. 2020.

LACAZ, F. A. de. A (Contra) Reforma Trabalhista: lei 13.467/2017, um descalabro para a Saúde dos Trabalhadores. Editorial. Ciênc. saúde coletiva, Rio de Janeiro, v. 24, n. 3, p. 680, mar. 2019. Disponível em: <https://www.scielosp.org/article/csc/2019.v24n3/680-680/>. Acesso 
em: 02 set. 2020 .

LÖWY, M. As aventuras de Karl Marx contra o Barão de Munchahüssen. Marxismo e positivismo na Sociologia do Conhecimento. 5. ed. São Paulo: Busca Vida, 1987.

LUCE, M. Teoria Marxista da Dependência. Problemas e categorias Uma visão histórica. São Paulo: Expressão Popular. 2018.

LUKÁCS, G. El asalto a la razón. 2. ed. Barcelona: Instrumentos 8; Grijalbo, 1976.

MARINI, R. M. Dialética da dependência. Petrópolis: Vozes, 2000. . Dialética da dependência. In: TRASPADINI, R.; STEDILE, J.P. (orgs.) Ruy Mauro Marini - Vida e Obra. São Paulo: Expressão Popular, 2011. p. 131-172.

. O ciclo do capital na economia dependente. In: FERREIRA, C. et al (orgs). Padrão de reprodução do capital: contribuições da TMD. São Paulo: Boitempo, 2012. p. 21-35.

. O Estado de Contrainsurgência. Revista de Estudos e Pesquisas sobre as Américas, v. 12, n. 3, p. 1-15. 2018. Disponível em: $<$ https://periodicos.unb.br/index.php/repam/article/download/ 20985/19316> Acesso em: 20 set. 2020.

MATTOS, F. Do conservadorismo à tradição marxista: rumos políticos do Serviço Social na previdência. R. Katál., Florianópolis, v. 18, n. 2, p. 182-190, p. 182-190, jul./dez. 2015.

MATTOS, M B. Sete notas: introdutórias como contribuição ao debate da esquerda socialista no Brasil. Rio de Janeiro: Consequência, 2017. 
MÉSZÁROS, I. A crise estrutural do capital. São Paulo: Boitempo, 2009.

MOURA, C. Escravismo, colonialismo, imperialismo e racismo. Revista Afro-Ásia, n. 14, p. 124-137, Instituto Brasileiro de Estudos Africanistas: São Paulo. 1983.

. Sociologia do negro brasileiro. São Paulo: Editora Ática, 1988.

O racismo como arma ideológica de dominação. Fundação Maurício Grabois, p. 28-38, ago./set./out. Edições 34.1994.

OLIVEIRA, A. C.; SOUZA, G.; SOARES, M. Capitalismo dependente brasileiro: retrocessos sociais e avanço do conservadorismo reacionário em tempos de crise. In: RAMOS, A. et al. (Orgs.) Desenvolvimento, formação social brasileira e políticas públicas: subsídios analíticos para o Serviço Social. Uberlândia: Navegando Publicações, p.11-24. 2019.

POGGI, T. Tempos de desencanto. As raízes profundas do ódio e da violência no tempo presente. In: ALMEIDA, J. R. de et al. (orgs.). Política e violência. Desafios contemporâneos. Curitiba: Prismas, 2016.

RODRIGUES, R. N. As Raças Humanas e a Responsabilidade Penal no Brasil. Salvador: Livraria Progresso, 1957.

Os africanos no Brasil. Rio de Janeiro: Centro Edelstein de Pesquisas Sociais, 2010.

SCHWARCZ, L. M. O espetáculo das raças - cientistas, instituições e questão racial no Brasil 1870-1930. São Paulo: Companhia das Letras, 2007.

SEVERO, V. S.; MAIOR, J. L. S. Manual da reforma trabalhista. 
Pontos e contrapontos. Porto Alegre/São Paulo: Editora Sensus, 2017.

SOUZA, J. M. A. de; SITCOVSKY, M. Direitos humanos, democracia e neoconservadorismo. Rev. katálysis, Florianópolis, v. 23, n. 2, p. 196198, ago. 2020. Disponível em: <https://www.scielo.br/scielo.php? script $=$ sci_arttext\&pid $=$ S1414-49802020000200196\&tlng=pt $>$. Acesso em: 10 set. 2020 .

SKIDMORE, T. E. Preto no branco: raça e nacionalidade no pensamento brasileiro. Rio de Janeiro: Paz e Terra, 1976.

TEIXEIRA, S. O. Que democracia? Soberania popular ou soberania do mercado? In: BOSCHETTI, I.; BEHRING, E.; SANTOS, S.; MIOTO, R. (orgs.). Capitalismo em crise, política social e direitos. São Paulo: Cortez, 2010. p. $131-151$

WOOD, E. M. Democracia contra capitalismo: a renovação do materialismo histórico. São Paulo: Boitempo, 2003. 